\title{
Phenolic content and antioxidant activity of Armenian cultivated and wild grapes
}

\author{
Kristine Margaryan ${ }^{1,2}$, Gagik Melyan ${ }^{3}$, Diana $\operatorname{Vardanyan}^{1}$, Hakob Devejyan ${ }^{2}$, and Rouben Aroutiounian ${ }^{1,2}$ \\ ${ }^{1}$ Department of Genetics and Cytology, Yerevan State University, 1 Alex Manoogian, 0025 Yerevan, Armenia \\ ${ }^{2}$ Research Group of Plant Genetics and Immunology, Institute of Molecular Biology of National Academy of Sciences RA, 7 \\ Hasratyan, 0014 Yerevan, Armenia \\ ${ }^{3}$ Scientific Center of Viticulture, Fruit-Growing and Wine-Making of the Armenian National Agrarian University, 1139 Merdzavan, \\ Armenia
}

\begin{abstract}
Nowadays the mobilization and conservation of Armenian grapevine genetic resources is becoming global concern and has crucial importance. Armenia is regarded as homeland of viticulture and earliest 'wine culture'. Being studied enough by the methods of ampelography, Armenian grapevine diversity needs to be investigated in accordance with the modern European requirements. In recent years, grape phenolics have been a theme of major scientific and applied interest. These metabolites contribute to grapes and wine sensory properties, such as color, flavor, astringency, and determines the strong antioxidant capacity. The purpose of the presented research was the evaluation of total phenolic content and antioxidant property of forty Armenian aboriginal varieties, interspecific and intraspecific hybrids and wild species with different genetic background and geographic origin. The realized research has revealed a notable difference among the cultivated varieties and wild species in the total phenolic content and antioxidant activity, increased the scientific knowledge about the aboriginal varieties and wild genotypes. Obtained results will support the importance of preserving the biological diversity and favor the reintroduction of grape cultivars and wild genotypes thanks to the present valorization.
\end{abstract}

\section{Introduction}

The awareness of the necessity for the protection and characterization of genetic diversity of the cultivated grapevine and its wild ancestor Vitis vinifera L. subsp. sylvestris is very high. Measures and actions to safeguard the existing germplasm diversity are increasing in all wine growing countries. The conservation and sustainable use of grapevine genetic resources depends on comprehensive description, characterization and the effective management of germplasm collections. This ensures their survival and use in breeding, research and viticulture.

Worldwide, Vitis genus consists from about 60 grapevine species but, among them, $V$. vinifera $\mathrm{L}$. is the most widely cultivated. In Armenia, viticulture is particularly rich with numerous autochthonous genotypes and wild species and grapevine biodiversity completes a part of the territory, tradition and history. These events are the result of both natural and human-induced selections that, through the centuries, have led to a strong relationship between cultivars and environment [1-3]. In fact, grapevine organoleptic and nutraceutical features are strongly associated with the geographical areas where vines grow [4]. This phenomenon is due to evolutionary mechanisms according which plants develop specific biosynthetic pathways, able to produce secondary metabolites, in order to protect vegetal tissues from biotic and abiotic stresses and to promote their propagation [5].

Therefore, the metabolic profile can be used as a biochemical marker for the characterization and the identification of grapevine varieties. In $V$. vinifera berries phenolic compounds are the most abundant among the secondary metabolites. These molecules are characterized by a basal structure of an aromatic ring with one or more hydroxyl groups and they are classified into several classes (simple phenols, phenolic acids, coumarins), according to their additional chemical subunits and number, type and orientation of their substituents. In particular, plant phenolic substances presenting more than one benzenic ring are usually known as polyphenols (flavonoids, stilbenes, lignans, tannins) [6,7]. Phenolic compounds are predominantly accumulated in berries skins and seeds.

For this reason, grape residue extract has become popular in recent years as a nutritional supplement. However, although the literature abounds with reports about phenolic compounds of grape seeds or skins, there are very few reports comparing distributions of phenolic compounds between seeds and skins among different wild species and cultivated varieties.

Knowledge of the phenolic compound distribution between seed and skin in a berry will contribute to a more comprehensive assessment of the berry biological activities. In the literature, several studies demonstrated that phenolic compounds play an important role in regulating the oxidative status of plant cells $[8,9]$. In fact, the free-radical scavenging activity of these molecules was clearly confirmed and associated with specific structural elements as the number, position and chemistry of the substituents, presence of double bonds, methylations and degree of polymerization [10]. For these reasons, a lot of 
research teams also investigated the antiradical effect of secondary metabolites. Among them, vine and wine gained special interest, since the antioxidant activity of some of its constituents, such as the proanthocyanidins, was found to be 20 times greater than vitamin $\mathrm{E}$ and 50 times greater than vitamin C [11].

This work represents the part of a national project whose objective was the study and the conservation of autochthonous, rare and neglected grapevines and wild species, in order to increase knowledge about local genotypes and to preserve Armenian grape biodiversity from extinction, essentially due to globalization, and the agronomic cultural heritage. It has been well known that the grape nutritional qualities are affected by environmental, cultural, and post-harvesting conditions, but the genotype is the main determinating factor, leading to the variation $[12,13]$. The knowledge of health-beneficial nutrition distribution among cultivated and wild grape species is very important for improving grape nutritional properties by breeding. European grapes commercially spreads around the world and their phenolic compounds and antiradical activities have been well studied but Armenian grape germplasm have yet to be fully explored for their bioactive constituents and nutritional activities.

The goal of the presented research was the evaluation of total phenolic content and antioxidant property of forty Armenian aboriginal varieties, interspecific and intraspecific hybrids and wild species with different genetic background and geographic origin. The realized research is planned to improve the assessment of phenolic compounds and to better understand their distributions in grape seeds and skin.

\section{Material and methods}

\subsection{Plant material}

The present research includes forty aboriginal varieties, interspecific and intraspecific hybrids and wild species. Grapes were harvested at their technological maturity, from four province of Armenia - Syuniq as southernmost, Tavush as northeast, Vayots Dzor as southeastern and Armavir as western part of Armenia during 2016 vintage. General descriptions of the grape varieties and wild species are given in Table 1. Grapes free from visible blemish or disease were selected. Three separate batches of grapes from different sites were used to prepare triplicate samples. For quantitative analysis, 100 to 150 grape berries, randomly selected from each grape accession, were collected for extraction. All data collected for each grape variety and wild species were reported as mean \pm SD for at least three replications

\subsection{Sample preparation}

The selected berries were finger pressed to remove juice and pulp. Seeds and skin were separated, washed several times with distilled water, and moisture was absorbed on blotting paper. The skins and seeds were then extracted in $20 \mathrm{ml}$ of an ethanol: water: hydrochloric acid (70:29:1) solution for 24 hours at room temperature. The extracts were filtered before the total phenolics spectrophotometric determination.

\subsection{Analysis of total polyphenols}

The Folin-Ciocalteu method was used for the determination of the total polyphenols as suggested by L. Rustioni et al., 2014 [14]. In brief, an aliquot $(0.5 \mathrm{ml})$ of the appropriate diluted skin and seed extracts were added to a $10 \mathrm{~mL}$ volumetric flask, containing $2.5 \mathrm{ml}$ of distilled water. Then, $0.5 \mathrm{ml}$ of Folin-Ciocalteu reagent was added and the contents mixed. After $3-5 \mathrm{~min}, 2 \mathrm{ml}$ of $10 \%$ $\mathrm{Na}_{2} \mathrm{CO} 3$ solution was added and made up to a total volume of $10 \mathrm{ml}$ distilled water. After keeping the samples for $90 \mathrm{~min}$ at room temperature extracts absorbance was read at $700 \mathrm{~nm}$ against distilled water as the blank. The total polyphenols were expressed as catechin $\left(\mathrm{mg} \cdot \mathrm{L}^{-1}\right)$ concentration and calculated applying the formula:

$$
\text { Catechin }\left(m g \cdot L^{-1}\right)=186.5 \times E_{700} \times d
$$

where $E_{700}=$ absorbance at $700 \mathrm{~nm} ; \mathrm{d}=$ dilution. Then data were converted in $\mathrm{mg} / \mathrm{kg}$ of grape, based on the fresh berries weights. All samples were prepared in triplicate.

\subsection{Free radical-scavenging activity on DPPH}

Free radical-scavenging ability of grape skin and seed extracts was determined by use of a stable 2,2-diphenyl2-picrylhydrazyl radical (DPPH). The DPPH assay was based on the slightly modified method of Brand-Williams et al. [15]. Briefly, $100 \mu 1$ of adequately diluted sample was added to $3.9 \mathrm{ml}$ methanolic solution of DPPH $\left(0.0025 \mathrm{~g} / 100 \mathrm{ml} \mathrm{CH} \mathrm{CH}_{3} \mathrm{OH}\right)$. The mixture was vigorously shaken and then incubated for $30 \mathrm{~min}$ in the dark. The reduction of the DPPH radical, after addition of the grape skin and seed extract, was determined by measuring the absorbance of the mixture at $517 \mathrm{~nm}$ (SpectrumLab Gold S54T). All determinations were performed in triplicate. The affinity of the test material to quench DPPH radicals was calculated using the following equation:

$$
\% I C=\left\{\left(A_{\text {Blank }}-A_{E}\right) / A_{\text {Blank }}\right\} * 100
$$

where $\% I C$ is the Inhibitory Concentration of the radical scavenging activity, $\mathrm{A}_{\text {Blank }}$ is the absorbance of the control sample and $\mathrm{A}_{E}$ is the absorbance of the grape extract in the presence of DPPH molecules.

Statistical methods: All data were expressed as mean \pm standard deviation (SD) of three replications for each grape skin and seed extracts tested. The data obtained were analyzed statistically by the one-way analysis of variance (ANOVA) and Multiple Range Test (STATGRAPHICS Plus).

\section{Results and discussion}

\subsection{Total phenolic content}

Spectrophotometric analysis was carried out to get insight into the phenolic content of grape skin and seed extracts of forty Armenian aboriginal varieties, interspecific and intraspecific hybrids and wild species.

The content of total phenols found in cultivated grape varieties traditionally grown in Armenia and wild species is presented in Table 2. According to the obtained results, the total phenolic content determined in aboriginal sample skins varied between $1296.6 \mathrm{mg} / \mathrm{kg}$ of grape and $272.5 \mathrm{mg} / \mathrm{kg}$ of of grape. "Garan dmak" presented the 
Table 1. Species and pedigree Armenian grape genotypes.

\begin{tabular}{|c|c|c|c|}
\hline Grape Genotypes & Pedigree & Parents & Colour \\
\hline Tchilar & V. vinifera & aboriginal & white \\
\hline Garan dmak & V. vinifera & aboriginal & white \\
\hline Mskhali & V. vinifera & aboriginal & white \\
\hline Arevik & V. vinifera & aboriginal & white \\
\hline Qrdi khaghogh & V. vinifera & aboriginal & yellow \\
\hline Mormor & V. vinifera & aboriginal & yellow \\
\hline Hakobi vordi & V. vinifera & aboriginal & rose \\
\hline Krhagi karchevan & V. vinifera & aboriginal & red \\
\hline Kakhet & V. vinifera & aboriginal & black \\
\hline Meghri vahravar (Shireyi) & V. vinifera & aboriginal & black \\
\hline Sali & V. vinifera & aboriginal & black \\
\hline Sev krop & V. vinifera & aboriginal & black \\
\hline Vardananq & V. vinifera & Madeleine Angevine $\times$ Yanvarskiy chyorniy & black \\
\hline Narekaci & V. vinifera & Ichikmar $\times$ Parkent & red \\
\hline Ayvazyani Vardabuyr & V. vinifera & Italia $\times$ Muscat Hamburg & white \\
\hline Itsaptuk & V. vinifera & Katta Kurgan $\times$ Kishmish khishrau & white \\
\hline Parvana & V. vinifera & Kata kurgan $\times$ Kishmish khishrau & white \\
\hline Hayastan & V. vinifera & Nimrang $\times$ Italia & white \\
\hline Hayastani quyry & V. vinifera & Nimrang $\times$ Italia & white \\
\hline Tzeni & V. vinifera & Nimrang $\times$ Italia & white \\
\hline Shahumyani & V. vinifera & Khushaine beliy O.P. & white \\
\hline Anahit & V. vinifera & Nimrang $\times$ Muscat Hamburg & white \\
\hline Berqanush & V.vinifera & C - 484 (Madeleine Angevine $\times$ Shasla muskatnaya) $\times$ No979/2 & white \\
\hline Arevshat & V.vinifera & Katta kurgan $\times$ Parkent & rose \\
\hline Arazi & V.vinifera & C-484 ( Madlen anjevin $\times$ Shasla muscatnaia) $\times$ Seneka & rose \\
\hline Aygezard & V. vinifera & Katta kurgan $\times$ Parkent & rose \\
\hline Armenia & V. vinifera & Khushayne beliy $\times$ Sateni cherniy & black \\
\hline Hayreniq & V. vinifera & Italia $\times$ Muscat Hamburg & black \\
\hline Charenci & V. vinifera $\mathrm{x}$ V.amurensis & Seyanets C 1262 (Amurensis $\times$ Zhemchug Saba) $\times$ Karmrahyut & black \\
\hline Nali & V. vinifera & unknown & white \\
\hline Megri vahravar (semiwild) & V. vinifera & unknown & black \\
\hline Wild grape Megri vahravar & Vitis vinifera ssp. sylvestris & & black \\
\hline Wild grape $1-8$ accessions & Vitis vinifera ssp. sylvestris & & black \\
\hline
\end{tabular}

highest total phenolic content (1296.6 mg/kg of grape), followed by "Kakhet", "Krhagi karchevan", "Sev crop" and "Sali" grape varieties. The total phenolic content of "Garan dmak", "Kakhet" and "Krhagi karchevan" grape varieties was significantly higher from other aboriginal varieties ( $p$ 0.05). "Garan Dmak" and "Kakhet" are common to Ararat valley and are used to make white and black wines respectively. "Krhagi karchevan" is a rare and long-neglected grape variety, grows in old vineyards of southernmost of Armenia (Syuniq Region, Meghri).

However, significant differences in skin total phenolic content were not found among "Tchilar", "Mskhali" and "Megri vahravar" and among "Sali" and "Sev crop" grape varieties $(p>0.05)$. Significantly lower skin total phenolic content was found in "Mormor" grape variety (272.5 mg/kg of grape) mainly preserved in old vineyards in southeastern of Armenia (Vayots Dzor Region). "Mormor" is characterized by biggest, grey berries and used to make wines with unique taste. Significant quantitative differences were identified also by comparing the total phenolic spectra of aboriginal grape seed extracts. "Kakhet" variety had the highest total phenolic content in seeds $(620.33 \mathrm{mg} / \mathrm{kg}$ of grape), followed by "Tchilar" (504.68 mg/kg of grape) and "Hakobi vordi" (493.86 $\mathrm{mg} / \mathrm{kg}$ of grape) varieties, while the lowest appeared in the "Qrdi khaghogh" ( $85.87 \mathrm{mg} / \mathrm{kg}$ of grape). Significant differences in seed total phenolic content were not found among "Arevik", "Mormor", "Meghri vahravar, Shireyi" and among "Sali" and "Sev crop" grape varieties $(\mathrm{p}>0.05)$.

In accordance with the presented results, the skin total phenolic content determined in interspecific and intraspecific hybrids varied between $1355.6 \mathrm{mg} / \mathrm{kg}$ of grape and $154.0 \mathrm{mg} / \mathrm{kg}$ of of grape. "Berqanush" presented the highest total phenolic content $(1355.6 \mathrm{mg} / \mathrm{kg}$ of grape), followed by "Vardananq" ( $953.8 \mathrm{mg} / \mathrm{kg}$ of grape), "Meghri vahravar" (semiwild) ( $887.00 \mathrm{mg} / \mathrm{kg}$ of grape)", "Charenci" (802.8 mg/kg of grape) hybrids. The parents of "Berqanush" hybrid are C - 484 (Madeleine Angevine x Shasla muskatnaya) x No979/2 (Spitak Araqseni x Chyorniy sladkiy). "Berqanush" is wine variety and common to Ararat valley and Vayots Dzor Region. However, significant differences in skin total phenolic content of interspecific and intraspecific hybrids were not found among "Itsaptuk", "Armenia", "Nali" varieties.

The total phenolic compounds in grape seeds of interspecific and intraspecific hybrids varied significantly. Among the grape cultivars studied "Meghri vahravar" (semiwild)" had the highest total phenolic contents in seeds $(725.2 \mathrm{mg} / \mathrm{kg}$ of grape), followed by "Berqanush" hybrid $(534.5 \mathrm{mg} / \mathrm{kg}$ of grape), while the lowest appeared in the "Shahumyani" and "Aygezard" hybrids.

Owing to recent prospections in Armenian woods and river floodplains, many forms of wild grapevine 
Table 2. Content of total phenols in Armenian grape genotypes.

\begin{tabular}{|c|c|c|}
\hline Grapevine genotypes & Skin phenolic content (mg/kg of grape FW) & Seed phenolic content (mg/kg of grape FW) \\
\hline \multicolumn{3}{|c|}{ Aboriginal grapes } \\
\hline Tchilar & $494.13 \pm 17.72 b c$ & $504.68 \pm 16.78 \mathrm{~g}$ \\
\hline Garan dmak & $1296.63 \pm 15.53 f$ & $418.43 \pm 13.10 \mathrm{e}$ \\
\hline Mskhali & $494.97 \pm 19.22 \mathrm{bc}$ & $480.40 \pm 7.27 \mathrm{ef}$ \\
\hline Arevik & $699.9 \pm 19.92 \mathrm{~d}$ & $243.07 \pm 9.40 \mathrm{~cd}$ \\
\hline Qrdi khaghogh & $552.27 \pm 16.09 \mathrm{c}$ & $85.87 \pm 5.10 \mathrm{a}$ \\
\hline Mormor & $272.47 \pm 15.12 \mathrm{a}$ & $295.38 \pm 12.78 d$ \\
\hline Hakobi vordi & $372.13 \pm 15.94 \mathrm{ab}$ & $493.86 \pm 31.08 \mathrm{~g}$ \\
\hline Krhagi karchevan & $1244.87 \pm 16.62 \mathrm{f}$ & $185.33 \pm 17.55 \mathrm{bc}$ \\
\hline Kakhet & $1251.50 \pm 15.01 \mathrm{f}$ & $620.33 \pm 10.4 \mathrm{~h}$ \\
\hline Meghri vahravar (Shireyi) & $506.73 \pm 12.42 \mathrm{bc}$ & $297.11 \pm 11.03 \mathrm{~d}$ \\
\hline Sali & $1005.77 \pm 12.32 \mathrm{e}$ & $150.34 \pm 11.03 \mathrm{ab}$ \\
\hline Sev krop & $1105.94 \pm 12.57 \mathrm{e}$ & $127.03 \pm 4.70 \mathrm{ab}$ \\
\hline \multicolumn{3}{|c|}{ Interspecific and intraspecific hybrids } \\
\hline Vardananq & $953.80 \pm 11.47 \mathrm{jk}$ & $274.51 \pm 10.1 \mathrm{~g}$ \\
\hline Narekaci & $681.53 \pm 14.73 \mathrm{~h}$ & $362.15 \pm 16.00 \mathrm{~h}$ \\
\hline Ayvazyani Vardabuyr & $333.77 \pm 16.67 \mathrm{e}$ & $173.32 \pm 9.37 \mathrm{def}$ \\
\hline Itsaptuk & $569.03 \pm 13.98 \mathrm{~g}$ & $283.20 \pm 12.78 \mathrm{~g}$ \\
\hline Parvana & $279.57 \pm 14.84 \mathrm{de}$ & $200.27 \pm 13.31 \mathrm{f}$ \\
\hline Hayastan & $264.77 \pm 5.65 \mathrm{cde}$ & $165.54 \pm 9.18 \mathrm{def}$ \\
\hline Hayastani quyry & $186.53 \pm 11.17 \mathrm{ab}$ & $247.58 \pm 16.92 \mathrm{~g}$ \\
\hline Tzeni & $234.57 \pm 14.03 \mathrm{bcd}$ & $149.01 \pm 1.03 \mathrm{cde}$ \\
\hline Shahumyani & $154.00 \pm 17.51 \mathrm{a}$ & $75.08 \pm 14.19 \mathrm{a}$ \\
\hline Anahit & $436.80 \pm 11.41 \mathrm{f}$ & $288.44 \pm 31.06 \mathrm{~g}$ \\
\hline Berqanush & $1355.57 \pm 17.13 \mathrm{k}$ & $534.79 \pm 17.76 \mathrm{i}$ \\
\hline Arevshat & $210.70 \pm 8.30 \mathrm{abcd}$ & $102.30 \pm 8.13 \mathrm{abc}$ \\
\hline Arazi & $204.67 \pm 13.01 \mathrm{abc}$ & $161.85 \pm 12.56 \mathrm{def}$ \\
\hline Aygezard & $160.60 \pm 16.14 \mathrm{a}$ & $85.87 \pm 5.10 \mathrm{ab}$ \\
\hline Armenia & $512.57 \pm 13.80 \mathrm{~g}$ & $137.58 \pm 12.69 \mathrm{cde}$ \\
\hline Hayreniq & $712.77 \pm 12.05 \mathrm{~h}$ & $394.61 \pm 18.42 \mathrm{~h}$ \\
\hline Charenci & $802.80 \pm 13.32 \mathrm{i}$ & $176.56 \pm 12.00 \mathrm{ef}$ \\
\hline Nali & $554.57 \pm 13.14 \mathrm{~g}$ & $127.72 \pm 12.59 \mathrm{bcd}$ \\
\hline Megri vahravar (semiwild) & $887.00 \pm 12.10 \mathrm{j}$ & $725.24 \pm 17.72 j$ \\
\hline \multicolumn{3}{|c|}{ Wild grapes } \\
\hline Wild grape Megri vahravar & $1160.17 \pm 17.44 \mathrm{e}$ & $1263.29 \pm 10.82 \mathrm{~d}$ \\
\hline Wild grape 1 & $2911.50 \pm 11.38 \mathrm{~g}$ & $2385.29 \pm 14.72 \mathrm{f}$ \\
\hline Wild grape 2 & $527.03 \pm 16.18 \mathrm{~b}$ & $648.89 \pm 17.82 \mathrm{c}$ \\
\hline Wild grape 3 & $944.94 \pm 18.54 d$ & $489.27 \pm 12.63 b$ \\
\hline Wild grape 4 & $328.20 \pm 18.97 \mathrm{a}$ & $325.51 \pm 14.63 \mathrm{a}$ \\
\hline Wild grape 5 & $339.47 \pm 18.52 \mathrm{a}$ & $372.98 \pm 14.42 \mathrm{a}$ \\
\hline Wild grape 6 & $838.67 \pm 10.59 \mathrm{c}$ & $349.86 \pm 12.70 \mathrm{a}$ \\
\hline Wild grape 7 & $911.67 \pm 15.91 \mathrm{~cd}$ & $597.76 \pm 14.07 \mathrm{c}$ \\
\hline Wild grape 8 & $2118.30 \pm 15.77 \mathrm{f}$ & $1819.19 \pm 17.47 \mathrm{e}$ \\
\hline
\end{tabular}

Values represent means of triplicate determination \pm S.D.

Data were analyzed by ANOVA and within each column different letters indicate statistically different values according to Multiple Range test at $\mathrm{p} \leq 0.05$.

Vitis vinifera ssp. sylvestris (approx. 3000 accessions) were discovered, which need to be maintained and characterized. The presented study just estimated the content of total phenolics and antioxidant capacity of wild species with different genetic background and geographic origin, when the quantitative significant differences by comparing the total phenolic spectra of wild grape skin and seeds extracts were identified. The total phenolics in berry skins of nine wild grapes ranged between $2911.50 \mathrm{mg} / \mathrm{kg}$ of grape and $328.20 \mathrm{mg} / \mathrm{kg}$ of grape with significant differences among the genotypes. We revealed that the Wild grape 1 contains significant high content of skin and seed total phenolics (2911.50 mg/kg of grape, 2385.29 $50 \mathrm{mg} / \mathrm{kg}$ of grape) respectively, followed Wild grape 8
$(2118.30 \mathrm{mg} / \mathrm{kg}$ of grape, $1819.19 \mathrm{mg} / \mathrm{kg}$ of grape) and Wild grape Megri vahravar $(1160.17 \mathrm{mg} / \mathrm{kg}$ of grape, $1263.2919 \mathrm{mg} / \mathrm{kg}$ of grape) respectively.

The obtained results showed that the total phenolic content of cultivated varieties and wild species was quite variable. In average, the content of total phenolics determined in wild species $(2035,8 \mathrm{mg} / \mathrm{kg}$ of grape) was significantly higher in comparison with aboriginal varieties $(1106,6 \mathrm{mg} / \mathrm{kg}$ of grape) and hybrids $(630,2 \mathrm{mg} / \mathrm{kg}$ of grape), $\mathrm{p} \leq 0.05$. The variability found in total phenolic content between different grape genotypes confirmed the hypothesis that genetic and environmental factors are key influencers of a cultivar's phenolic content. 


\subsection{DPPH radical-scavenging activity}

Analysis of DPPH radical-scavenging activity is widely used to evaluate the ability of free radicals to react with antioxidants. The measurement of the consumption of DPPH radical allows to determine exclusively the intrinsic ability of a substance to donate hydrogen atoms or electrons to this reactive species in a homogenous system. The method is based on the reduction of DPPH solution in the presence of a hydrogen donating antioxidant due to the formation of non radical form DPPH-H by the reaction blue-violet colour changes gradually to yellow and a decrease in absorbance at $517 \mathrm{~nm}$ is monitored during the reaction [16]. Free radicals cause the oxidation of biomolecules and leads to the cell injury and death. Free radical scavenging capacity was the predominant mechanism in the antioxidant activity of samples, indicating that phenolic antioxidants are potent free radical terminators.

In our study, all the extracts of cultivated and wild grape genotypes exhibited appreciable scavenging activity and ranging from 43.3 to $92.2 \%$ for aboriginal grape cultivars, from 32,4 to $80.9 \%$ for interspecific and intraspecific hybrids and from 40.61 to $65.48 \%$ for wild species. A regression analysis was used to correlate the results of total phenolic content and antioxidant activity detected in cultivated and wild genotypes (Figs. 1, 2, 3). For all analyzed aboriginal genotypes, hybrids and wild species the significant correlation was detected $\left(\mathrm{R}^{2}=0.887, \mathrm{R}^{2}=0.654\right.$ and $\left.\mathrm{R}^{2}=0.776, \mathrm{p} \leq 0.001\right)$ respectively.

Extracts of all the aboriginal grape varieties demonstrated DPPH radical scavenging activity, which suggests that, they all contained antioxidants. The highest antioxidative activity was revealed by extracts of "Garan dmak" and "Êakhet" cultivars, characterized by the highest concentration of total phenolics. The weakest antioxidative activity was found for the extract obtained from "Mormor" cultivar, demonstrated lowest content of total phenolics.

Among interspecific and intraspecific hybrids the highest capacity to scavenge DPPH free radicals was determined for an extract from "Vardananq", "Berqanush" and "Hayreniq" hybrids, demonstrated the highest concentration of total phenolics. Strong correlations suggested that the phenolic content of these varieties contributed significantly to the antioxidant capacities of grape extracts. Figure 3 showed that all the wild genotypes have a significant inhibitory activity against the DPPH radicals, but the higher inhibition of DPPH radical observed for Wild grape 1 and Wild grape 8 .

The obtained results demonstrated that scavenging activity was different between the cultivated grapes and wild species, which was due to the difference in their phenolic contents. One of the aims of the presented research was to determine the correlation between total phenolics and antioxidant activity in cultivated and wild grapes. Some researchers reported a strong correlation between antioxidant activity and total phenolics whereas others also indicated that total phenolics may be less significantly correlated with the antioxidant properties.

According to the results of the present screening study, we can emphasize on the great variability of total phenolic content and on the notable scavenging activity of studied grape genotypes.

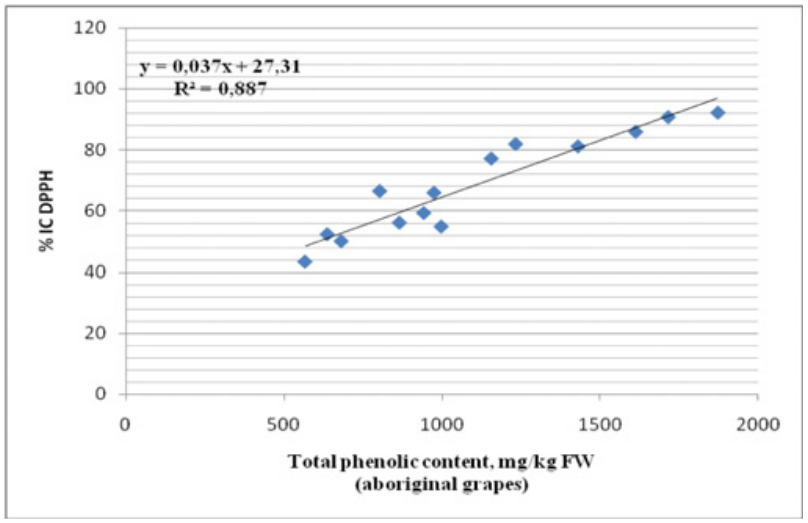

Figure 1. Linear regression between total phenolics and antioxidant activity (DPPH) of Armenian aboriginal grapes.

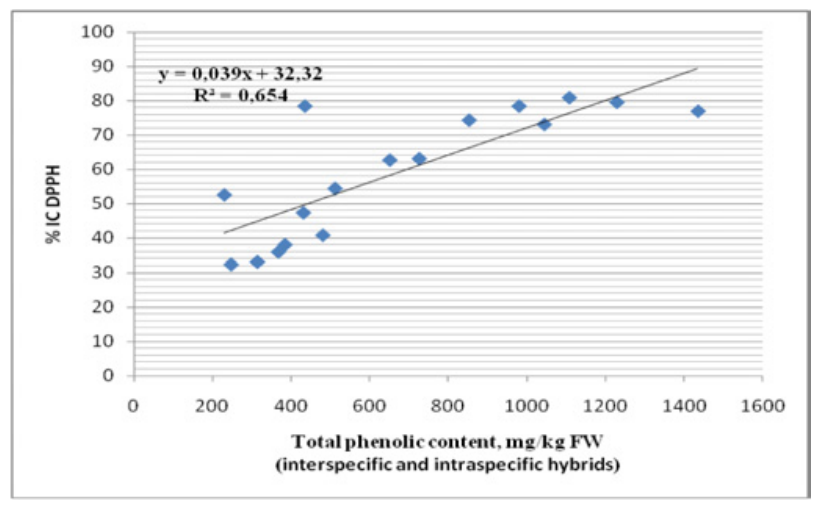

Figure 2. Linear regression between total phenolics and antioxidant activity (DPPH) of Armenian interspecific and intraspecific hybrids.

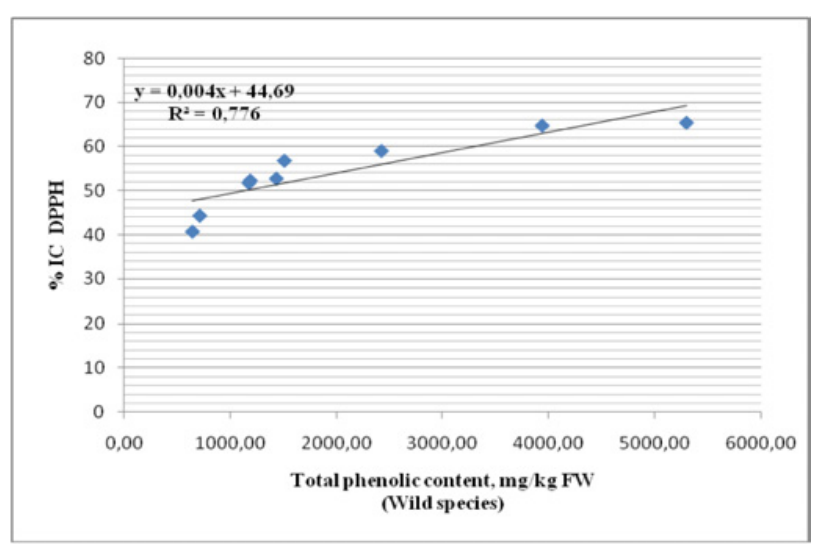

Figure 3. Linear regression between total phenolics and antioxidant activity (DPPH) of wild species.

Presented data indicates the marked antioxidant activity of Armenian cultivated and wild grape extracts strongly related with high content of total phenolics, acting as reductones by donating the electrons and reacting with free radicals to convert them into more stable product.

\section{Conclusions}

Knowledge of the phenolic compounds in grape berry seed and skin will contribute to more comprehensive assessment of their biological activities. The present 
research was aimed at characterizing forty Armenian $V$. Vinifera spp. Sativa and V. Vinifera spp. Sylvestris through the determination of their total phenolics and antioxidant activity.

The realized research has revealed a notable difference among the cultivated varieties and wild species in the total phenolic content and antioxidant activity decreasing in following order: wild species $>$ aboriginal varieties > interspecific and intraspecific hybrids. High levels of correlation between the total phenolics and antioxidant activity for all studied grape genotypes were revealed.

Obtained results will support the importance of preserving the genetic diversity and favor the reintroduction of grape cultivars and wild genotypes thanks to the present valorization. Finally, presented research will contribute to the sustainable development of agriculture in Armenia through establishing the basis for the improvement and modernization of the grape and wine production.

The present research was realized as a part of the project "The role of biodiversity of Armenian cultivated and wild grapevine in environmental balance", 15T-1E232.

\section{References}

[1] F. Mannini, I International Symposium on Grapevine Growing, Commerce and Research 652, 87-95 (2003)

[2] Z. Liang, C. L. Owens, G. Y. Zhong and L. Cheng, Food Chem. 129(3), 940-950 (2011)

[3] Z. Liang, L. Cheng, G. Y. Zhong and R. H. Liu, PLoS ONE 9(8), e105146 (2014)
[4] A. De la Cerda-Carrasco, R. López-Solís, H. NuñezKalasic, Á. Peña-Neira and E. Obreque-Slier, J. Sci. Food Agric. 52(14), 4360-4367 (2014)

[5] C. Manach, A. Scalbert, C. Morand, C. Rémésy and L. Jiménez, Am. J. Clin. Nutr. 79(5), 727-747 (2004)

[6] S. H. Nile, S. H. Kim, E. Y. Ko and S. W. Park, Biomed.Res. Int. 2013, 718065 (2013)

[7] L. M. Ramirez-Lopez, W. McGlynn, C. L. Goad and C. A. Mireles DeWitt, Food Chem. 149, 15-24 (2014)

[8] I. M. Huseynova, Biochim. Biophys. Acta 1817(8), 1516-1523 (2012)

[9] G. Di Marco, A. Gismondi, L. Canuti, M. Scimeca, A. Volpe and A. Canini, Plant Biol. 16(4), 792-800 (2014)

[10] K. E. Heim, A. R. Tagliaferro, D. J. Bobilya, J. Nutr. Biochem. 13(10), 572-584 (2002)

[11] J. Shi, J. Yu, J. E. Pohorly and Y. Kakuda, J. Med. Food 6(4), 291-299 (2003)

[12] A. M. Connor, J. J. Luby, C. B. S. Tong, C. E. Finn, J. F. Hancock, Journal of the American Society for Horticultural Science 1, 82-88 (2002)

[13] A. R. Proteggente, A. S. Pannala, G. Pagana, L.Van Buren, E. Wagner, S. Wiswman, et al., Free Radical Research 36, 217-233 (2002)

[14] L. Rustioni, D. Maghradze, C.F. Popescu, G. Cola, E. Abashidze, R. Aroutiounian et al., Vitis 53(4), 219-226 (2014)

[15] W. Brand-Williams, M. E. Cuvelier, C. Berset, Food Science and Technology-Lebensmittel-Wissenschaft and Technologie 28(1), 25-30 (1995)

[16] X. J. Duan, W. W. Zhang, X. M. Li, B. G. Wang, Food Chemistry 95(1), 37-43 (2006) 